\title{
CEREBELLAR GLIOBLASTOMA MULTIFORME IN AN ADULT
}

\author{
João Paulo Mattos ${ }^{1}$, Horacio Armando Marenco², \\ José Maria Campos², Andréa Vasconcellos Faria ${ }^{3}$, \\ Luciano Souza Queiroz ${ }^{4}$, Guilherme Borges ${ }^{5}$, Evandro de Oliveira ${ }^{5}$
}

\begin{abstract}
Cerebellar glioblastoma multiforme (GBM) is a rare tumor. This is the third case published in Brazilian literature and, the last one has been described more than 15 years ago. The aggressive behavior of GBM prompts for fast treatment, which can be hampered by the fact that the diagnosis of GBM requires a high degree of suspicion. We describe a case of GBM in a 46 years old man. In conjunction, we present a literature review including particular issues, clinical data, advances in imaging studies, pathological characteristics, treatment options and the behavior of such malignant tumor.
\end{abstract}

KEY WORDS: high grade astrocytoma, cerebellar glioblastoma multiforme, posterior fossa glioma.

\begin{abstract}
Glioblastoma multiforme cerebelar primário em um adulto
RESUMO - Glioblastoma multiforme (GBM) cerebelar é um tumor raro. Apresentamos o terceiro caso revisado em literatura neurológica brasileira, sendo o último descrito há mais de 15 anos. Devido a sua agre ssividade, o tratamento deve ser instituído rapidamente, porém certa indefinição quanto à conduta pode ocorrer, pois o diagnóstico de GBM pode não ser lembrado. Apresentamos um caso de GBM cerebelar em um homem de 46 anos. Também fazemos uma revisão a respeito de seu comportamento, quadro clínico e avanços quanto à investigação por imagem, aspectos histopatológicos, formas de tratamento e suas características peculiares.
\end{abstract}

PALAVRAS-CHAVE: as trocitoma de alto grau, glioblastoma multiforme cerebelar, glioma de fossa posterior.

Glioblastoma multiforme (GBM) is the most common primary central nervous system (CNS) tumor in adults comprising approximately $50 \%$ of all primary intracranial tumors. Primary cerebellar GBM is a rare tumor in adults ${ }^{1-7}$ and accounts for $1 \%$ of all GBM ${ }^{4}$. The reason for its rarity is not completely understood ${ }^{1-3,5}$. Differential diagnosis of GBM from other CNS lesions is an outstanding issue, especially in regard to its dif$f$ e rentiation from other primary CNS tumors such as the anaplasic astrocytoma and from metastase $\mathrm{s}^{5,7,8}$ since the prognosis and outcome is different. For this reason, neuroimaging and ultimately the immunostainning assessment are important tools for planning the therapeutic course.

We reporta case of an adult man with a cere be $1-$ lar GBM and a literature review concerning the clinical data, diagnosis including radiological and pathological aspects, treatment and its particular behavior is done.

\section{CASE}

A 46 years old man was admitted due to history of headache beginning 4 months before. Ventricle-peritoneal shunt was performed in another hospital due to acute hydrocephalus 1 month after the initial symptoms. The patient developed progressive cerebellar signs with gait disturbance, nystagmus and clumsiness of the extremities, more intense on the left side, and vomiting. He was unable to walk and showed mild degree of confusional state at examination. A magnetic resonance imaging (MRI) revealed an infiltrative mass situated in the left hemisphere and para-

Neurosurgery Division from Neurology Department, State University of Campinas (UNICAMP), Campinas SP, Brazil: ${ }^{1}$ M.D., Neurosurgeon; ${ }^{2}$ M.D., Resident of Neurosurgery; ${ }^{3}$ M.D., Neurorradiologist from Radiology Department; ${ }^{4}$ M.D., Ph.D., Professor of Neuropathology from Pathology Department; ${ }^{5}$ M.D., Ph.D. Professor of Neurosurgery.

Received 2 June 2005, received in final form 7 October 2005. Accepted 24 October 2005.

Dr. Horacio Armando Marenco - Av. Papa Pio XII 199 / 83 - 13070-091 Campinas SP - Brasil. E-mail: horacio.marenco@gmail.com 


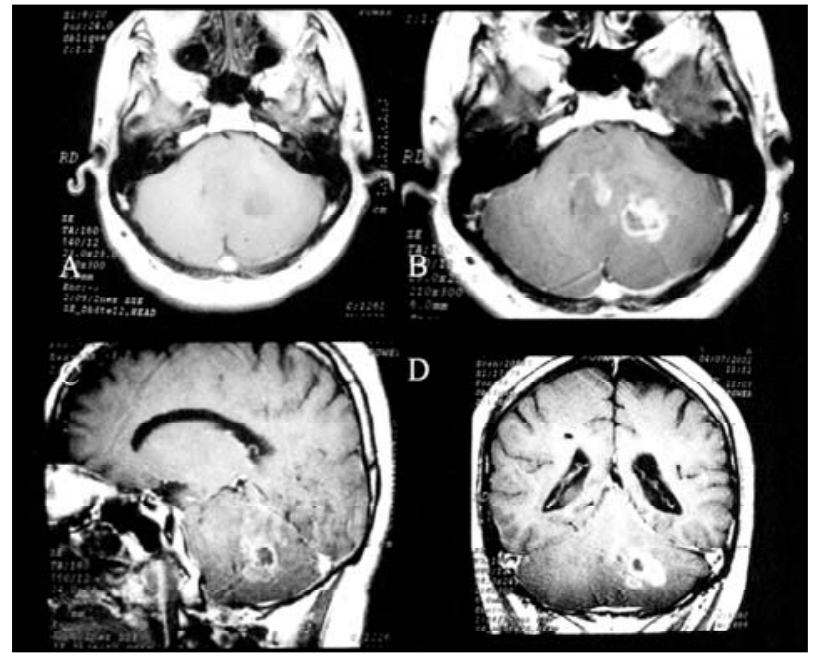

Fig 1. A) Axial T1-weighted image showing a decreased signal lesion in left cerebellar hemisphere; B) After paramagnetic con trast administration there is thick and irregular ring like enhancing nodules; C) Sagittal and D) coronal sections showing the same tumoral aspect.

median region of the cer ebellum showing central decreased signal in T1-weighted image and ring enhancement after paramagnetic contrast administration (Fig 1). The MRproton spectroscopy of the lesion demonstrate high choline peak (choline/creatinine ratio $=5.347$ ) in contrast to decre ased $\mathrm{N}$-acetil-aspartate (NAA) peak (NAA/creatinine ratio= 0.504) (Fig 2), suggesting a malignant neoplasm.

A stereotactic biopsy was performed followed by subtotal cerebellar tumoral resection after the confirmation of the histological (Fig 3) and immunostainning findings com-

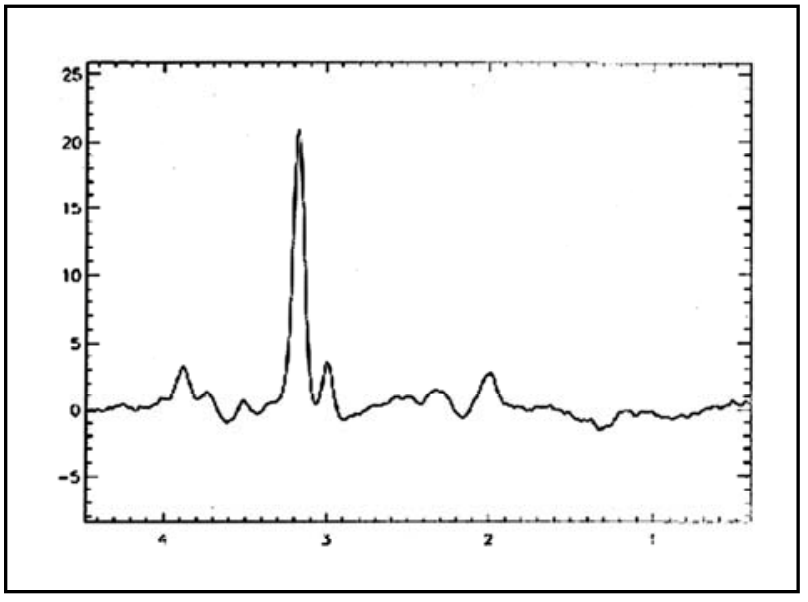

Fig 2. A spectroscopy showing the decreased NAA peak in con trast to high choline and lactate peak compatible with GBM pattern.

patible with GBM (glial fibrillary acidic protein + , S100 protein + , chromogranin + , neuron specific enolase + , neurofilament + ). Soon after the surgery the patient remained dependent upon mechanical artificial ventilation due to intracranial hypertension with cerebellar edema, from which he was successfully weaned and 6 days after the surgery, the patient was alert and oriented.

A 6 Gy dose of fractioned radiation therapy was delivered to posterior fossa beginning 34 days after surgical procedure. Chemotherapeutic agent (carmustine $80 \mathrm{mg} / \mathrm{m}^{2}$ ) was administered as adjuvant treatment. The patient kept his cerebellar deficit and improved his mental status. There were no more headaches or vomiting and the patient's Karnofsky perf o rmance scale showed an improvement fro $\mathrm{m}$

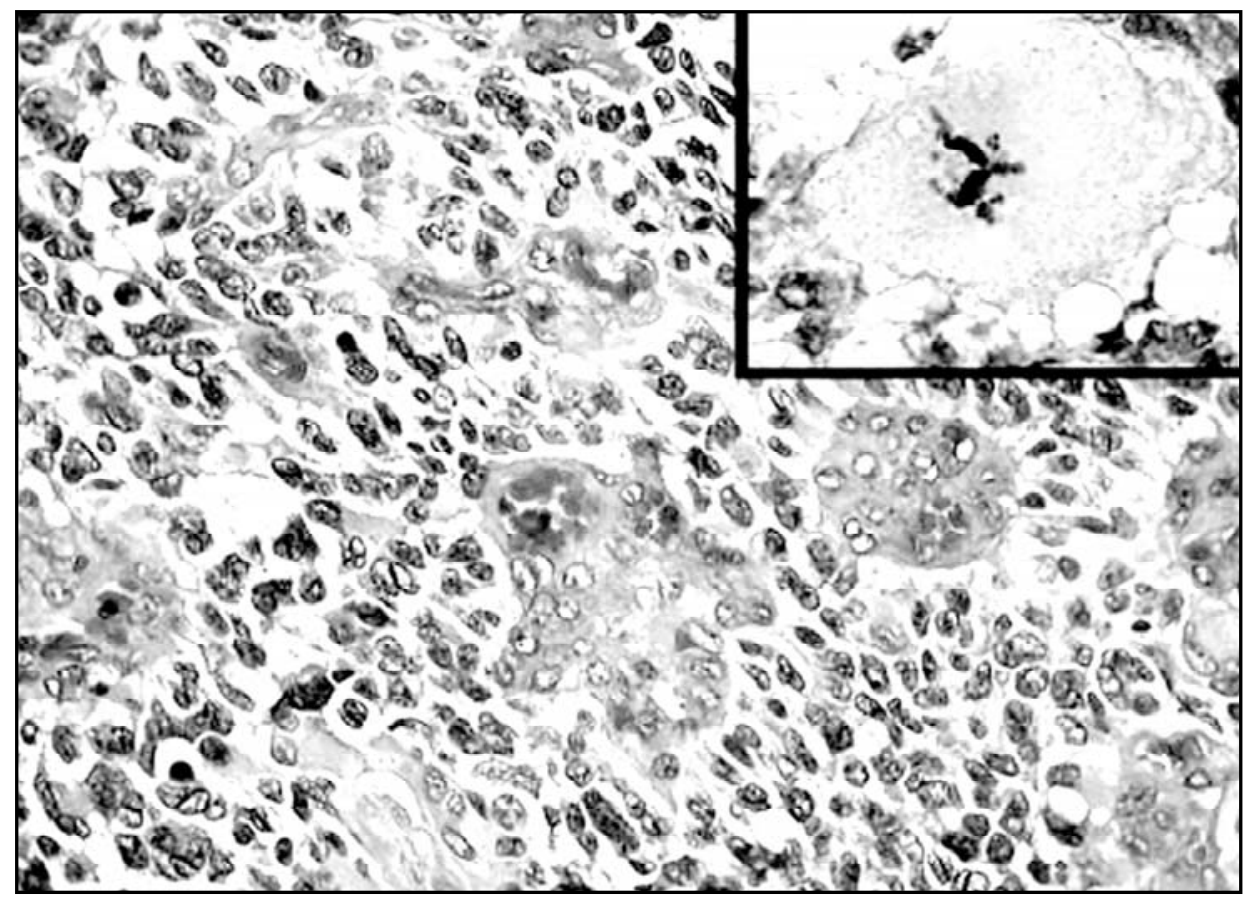

Fig 3. Small cell glial tumor with abundant vascular prolif eration (HEx100). Inset: Atypi cal mitosis in a large tumor cell (HEx 400). 
40 points, before treatment, to 90 points in 10 months postoperative follow up. Then, his clinical condition deteriorated and he died 18 months after surgery.

\section{DISCUSSION}

The clinical symptomatology of cerebellar lesions is usually similar, however, the time between initial complaints and diagnosis seems to be shorter in cases of cerebellar GBM compared to less malignant tumors with slower growth pattern. The most frequent symptoms are headache, nausea, vomiting and ataxia 1,3,5,9-11. Indeed, dizziness, neck pain and mental confusion $^{1,4,11}$ can be present. There is a male preponderance $^{5,12}$ and approximately two thirds of cases occur in adult age range, showing a peak incidence around the $6^{\text {th }}$ decade 5 and the second peak in the $1^{\text {st }}$ decade ${ }^{1}$.

The diff e rential diagnosis from metastases, cerebellar infarct with contrast enhancement and astrocytomas $^{3}$ is difficult. After the introduction of CT scan, the presence of solid tumor with contrast enhancement or those with central hypodensity suggesting n e c rosis was described in cerebellar $\mathrm{GBM}^{5}$. Later, the lack of peritumoral edema found in $\mathrm{CT}$ scans of cerebellar GBM was described as one way to diffe re $n \mathrm{ti}$ ate from metastatic lesions ${ }^{5,11}$. Moreover, CT scan can be useful to diff e rentiate brainstem GBM from cerebellar GBM.

MRI increased the accuracy to define the nature of the lesion. In general, there is decreased T1 and increased T2-weighted signal intensities with heterogeneous ring like enhancement after contrast administration ${ }^{8}$. Intratumoral hemorrhage is suggested by mixed signal and poorly defined margins. Concomitant multifocal or multicentric lesions are other features helping the diffe rential diagnosis ${ }^{8}$. The proton spe ct roscopy of astrocytomas shows a significant reduction in NAA due to loss of neuronal elements, and elevation of choline peak that may reflect increased membrane synthesis. The presence of lactate peak correlates with higher degree of malignance commonly observed in $\mathrm{GBM}^{13}$.

The theory of cerebellar GBM originated from embrionarycells was changed by the proposition of anaplasic progression of mature cerebellar astrocytic cells ${ }^{10}$. However, there is controversy concerning the primary origin of $\mathrm{GBM}^{9}$ or secondary anaplasic change from diffuse astrocytomas to GBM ${ }^{1}$. Although most authors failed to show the explanation for the rarity of cerebellar $\mathrm{GBM}^{2,3,9,10}$ there is a description of the lesser tendency of cerebellar astrocytes to become malignant ${ }^{1}$. The development of GBM following pilocytic astrocytoma, medulloblastoma and other posterior fossa midline tumors is described ${ }^{6,7,14}$. However, it remains difficult to prove their malignant transformation since most of those cases were submitted to radiation therapy post operatively showing that there is a possibility to anaplasic astrocitic evolution of those cells after this kind of therapy and the GBM may be then a second tumor.

The use of radiation therapy (XRT) after radical surgical resection is a well established modality of treatment ${ }^{1,11}$. The extent of XRT is not yet defined. Craniospinal XRT is a reasonable decision if cerebrospinal fluid (CSF) dissemination is considered as in chil$d$ ren, who seem to have higher chances of CSF dissemination than adults ${ }^{11}$. There is a tendency for limited posterior fossa radiation therapy ${ }^{2,11,12}$. The craniospinal axis dissemination is usually found when local recurrence occurs. This fact has been used to advocate higher XRT doses around 5 Gy limited to posterior fossa ${ }^{2,12}$. Chemotherapy is not well established but is the only reasonable adjuvant treatment for very young children ${ }^{11}$.

The biological behavior of cerebellar and supratentorial GBM is similar ${ }^{1,15}$. On the other hand, it is possible that cerebellar GBM found in young patients has a better prognosis like anaplasic astrocytomas (AA) which has a longer survival than GBM variant. The median survival for GBM is around 18 months ${ }^{11}$ in contrast to 32 months in the same study for AA2. Survival is higher for $A A^{2,12}$, justifying the need for early diagnosis and differentiation from GBM.

The studies concerning molecular biology of GBM may offer important information about the origin of these tumors. These studies are hampered by the heterogeneous cell population within the same tumoral mass. The presence of tumoral clonal cell may p e rmit the definition of treatment targets and resea rch in this area has been done with promising results ${ }^{16}$

Although we have reported one case, we observed that prompt aggressive treatment provided the patient clinical improvement and longer survival period. The patient's evolution after surg e ry was as predicted in current medical literature, so we support this kind of approach for patients with cerebellar GBM. 


\section{REFERENCES}

1. Rosenfeld J, Rossi ML, Briggs M. Glioblastoma multiforme of the cerebellum in an elderly: a case report. Tumori 1989;75:626-629.

2. Chamberlain MC, Silver P, Levin VA. Poorly diff e rentiated gliomas of the cerebellum: a study of 18 patients. Cancer 1990;65:337-340.

3. Miller EM, Mani RL, Townsend JJ. Cerebellar glioblastoma multiforme in an adult. Surg Neurol 1976;5:341-343.

4. Pombo R, Tortelly-Costa A, Bulacio E, Hahn MD, Carvalho ML. Cerebellar glioblastoma multiforme: report of a case in a child. A rq Neuropsiquiatr 1985;43:102-107.

5. Occhiogrosso M, Spada A, Merlicco G, Vailati G, De Benedictis G. Malignant cerebellar astrocytoma: report of five cases. J Neurosurg Sci 1985;29:43-50.

6. Wi s offHS, Llena JF. Glioblastoma multiforme of the cerebellum five decades after irradiation of a cerebellar tumor. J Neurooncol 1989;7: 339-344.

7. Schmidbauer M, Budka H, Bruckner R, Vorkapic P. Glioblastoma developing at the site of a cerebellar medulloblastoma treated 6 years earlier: case report. J Neurosurg 1987;67:915-918.
8. Kuroiwa T, Numaguchi $Y$, Rothman, et al. Posterior fossa glioblastoma multiforme: MR findings. Am J Neuroradiol 1995;16:583-589.

9. Hegedus K, Molnar P. Primary cerebellar glioblastoma multiforme with an unusually long survival: case report. J Neurosurg 1983;58:589-592.

10. Aun RA, Stavale JN, Silva-Junior D. Glioblastoma multiforme of the cerebellum: report of a case. Arq Neuropsiquiatr 1981;39:350-354.

11. Kulkarni AV, Becker LE, Jay V, Armstrong DC, Drake JM. Primary cerebellar glioblastoma multiforme in children: report of four cases. J Neurosurg 1999;90:546-550.

12. Kopelson G. Cerebellar glioblastoma. Cancer 1982;50:308-311.

13. Fulham MJ, Bizzi A, Dietz MS, et al. Mapping of brain tumor metabolites imaging clinical relevance. Radiology 1992;176:509-515.

14. Ushio Y, Arita N, Yoshimine T, Ikeda T, Mogami H. Malignant recurrence of childhood cerebellar astrocytoma: case report. Neurosurgery 1987;21:251-255.

15. Luccarelli G. Glioblastoma multiforme of the cerebellum: description of three cases. Acta Neurochirur (Wien) 1980;53:107-116.

16. DiTomaso E, Pang JC, Lam HK, et al. Establishment and characterization of a human cell line from pediatric cerebellar glioblastoma multiforme. Neurophatol Appl Neurobiol 2000;26:22-30. 